\title{
The association of nephrolithiasis with metabolic syndrome and its components: a cross-sectional analysis
}

\author{
Yen-Tze Liu' \\ Pei-Yu Yang ${ }^{2}$ \\ Yu-Wen Yang' \\ Hung-Yu Sun' \\ I-Ching Lin ${ }^{1,3,4}$ \\ 'Department of Family Medicine, \\ Changhua Christian Hospital, \\ 2Department of Laboratory, Show \\ Chwan Memorial Hospital, Changhua \\ City, ${ }^{3}$ School of Medicine, Chung \\ Shan Medical University, Taichung \\ City, ${ }^{4}$ School of Medicine, Kaohsiung \\ Medical University, Kaohsiung City, \\ Taiwan
}

This article was published in the following Dove Press journal:

Therapeutics and Clinical Risk Management

6 January 2017

Number of times this article has been viewed
Background: Metabolic syndrome is a worldwide disorder and also the major risk factor of several systemic diseases. Evidence identifying the association between metabolic syndrome and nephrolithiasis is lacking, especially in Taiwan.

Aim: The aim of this study was to investigate the association between nephrolithiasis and metabolic syndrome and its components.

Design and setting: This was a cross-sectional study conducted in the Health Examination Department of a medical center in Changhua, Taiwan, from January 2010 to December 2010. Methods: We reviewed the medical records of patients who had visited the Health Examination Center of Changhua Christian Hospital in 2010. A total of 3,886 individuals were enrolled. According to the exclusion criteria, those with an age $<20$ years and an abnormal renal function were excluded. A total of 3,793 subjects were included. All $P$-values are two tailed, and $P<0.05$ was defined as statistically significant.

Results: The results showed a correlation between nephrolithiasis and metabolic syndrome and its components. The multivariate-adjusted odds ratio (OR) (95\% confidence interval [CI]) of metabolic syndrome for nephrolithiasis was $1.318(1.083-1.604)$, with a $P$-value of 0.006 . Larger waist circumference (multivariable-adjusted OR 1.338; 95\% CI 1.098-1.631; $P=0.004$ ), higher blood pressure (multivariable-adjusted OR 1.333; 95\% CI 1.106-1.607; $P=0.003$ ), and increased fasting glucose (multivariable-adjusted OR 1.276; 95\% CI 1.054-1.546; $P=0.01$ ) were associated with nephrolithiasis.

Conclusion: This is the first study in Taiwan to investigate the relationship between metabolic syndrome and nephrolithiasis. The mechanism is controversial, and several hypotheses are offered. Adequate lifestyle modification and proper treatment in metabolic syndrome management may both contribute to nephrolithiasis prevention.

Keywords: nephrolithiasis, metabolic syndrome, cross-sectional study, primary health care, preventive health services

\section{Introduction}

Metabolic syndrome is a worldwide, general metabolic disorder, with a year-by-year increasing prevalence. It is well known as a constellation of elevated fasting glucose, central obesity, dyslipidemia (raised triglycerides and lowered high-density lipoprotein cholesterol [HDL-C]), and raised blood pressure co-occurring within an individual. When these components are grouped together, they are associated with an increased risk of cardiovascular disease. ${ }^{1}$ However, the syndrome is associated with so many definitions that it is difficult to clarify its nature in both clinical practice and academic research. Therefore, the International Diabetes Federation (IDF) and the American
Department of Family Medicin

Changhua Christian Hospital, I 35

Nanxiao Street, Changhua City 500 ,

Changhua County, Taiwan

Tel +886 47238595 ext 4395

Fax +88647232942

Email licypy03@gmail.com
Therapeutics and Clinical Risk Management 2017:13 41-48

(c) (i) (5) 2017 Liu et al. This work is published and licensed by Dove Medical Press Limited. The full terms of this license are available at https://www.dovepress.com/terms.php

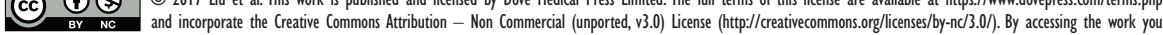
hereby accept the Terms. Non-commercial uses of the work are permitted without any further permission from Dove Medical Press Limited, provided the work is properly attributed. For permission for commercial use of this work, please see paragraphs 4.2 and 5 of our Terms (https://www.dovepress.com/terms.php). 
Heart Association/National Heart, Lung, and Blood Institute (AHA/NHLBI) cooperated to propose a unified definition of metabolic syndrome: ${ }^{2}$ three abnormal components out of five now define metabolic syndrome, with the five components comprising the following: 1) elevated waist circumference: population- and country-specific definitions; 2) elevated triglycerides: $\geq 150 \mathrm{mg} / \mathrm{dL}(1.7 \mathrm{mmol} / \mathrm{L})$ (drug treatment for elevated triglycerides is an alternate indicator); 3) reduced HDL-C: $<40 \mathrm{mg} / \mathrm{dL}(1.0 \mathrm{mmol} / \mathrm{L})$ in males and $<50 \mathrm{mg} / \mathrm{dL}(1.3 \mathrm{mmol} / \mathrm{L})$ in females (drug treatment for reduced HDL-C is an alternate indicator); 4) elevated blood pressure: systolic $\geq 130 \mathrm{mmHg}$ and/or diastolic $\geq 85 \mathrm{mmHg}$ (antihypertensive drug treatment in a patient with a history of hypertension is an alternate indicator); and 5) elevated fasting glucose: $\geq 100 \mathrm{mg} / \mathrm{dL}$ (drug treatment for elevated glucose is an alternate indicator).

Compared to the widely used definitions given by the National Cholesterol Education Program Adult Treatment Panel III in 2001 and the IDF in 2005, abdominal obesity is specified according to population and country in these jointly created criteria. ${ }^{3}$ The waist circumference thresholds for Asians currently recommended by both the IDF and the World Health Organization are $\geq 90 \mathrm{~cm}$ in males and $\geq 80 \mathrm{~cm}$ in females, the same as the criteria of Taiwan's Ministry of Health and Welfare. The importance of metabolic syndrome in Taiwan is evidenced by the doubling of its prevalence in the country from $13.6 \%$ to $25.5 \%$ based on two official Nutrition and Health Surveys (NAHSIT 1993-1996 and NAHSIT 2005-2008), which were conducted 12 years apart. ${ }^{4}$

The lifetime risk for kidney stone disease currently exceeds $6 \%-12 \%$ in the general population, ${ }^{5,6}$ and the prevalence and incidence rate of kidney stone disease are increasing globally and differ in terms of gender, race, and environment. ${ }^{5,7,8}$ More importantly, the association of nephrolithiasis with the components of metabolic syndrome including obesity, elevated blood pressure, dyslipidemia, and glucose intolerance has been found in recent studies. ${ }^{6,9,10}$ The definite causal relationship remains controversial, but some pathophysiological mechanisms have been discussed, such as abnormalities of renal calcium metabolism behind the association between hypertension and nephrolithiasis, decreasing urinary $\mathrm{pH}$ and defective ammonium excretion related to obesity and insulin resistance, and renal lipotoxicity caused by triglycerides.

Nephrolithiasis causes not only acute illness to patients who are suffering severe pain, but also numerous medical expenditures. If we could verify the relationship between nephrolithiasis and metabolic syndrome, we may prevent both of them by controlling the risk factors, especially in a healthy population. However, there is currently little evidence to support this relationship in a healthy population, especially in Asia. Because we lack the evidence to prove the correlation in healthy population in Taiwan, we conducted this study to investigate the association between nephrolithiasis and metabolic syndrome in a healthy population group.

\section{Methods}

We conducted a cross-sectional study in the Health Examination Center of Changhua Christian Hospital, Changhua City, Taiwan, from January 2010 to December 2010. The study protocol was approved by the Ethics Committee of Changhua Christian Hospital, Taiwan (CCH IRB No 150803). Because this was a retrospective study and all the personal data were delinked and unidentifiable, the Ethics Committee waived the requirement of obtaining patient consent.

\section{Study design and participants}

We retrospectively reviewed the medical records of those who visited the Health Examination Center of Changhua Christian Hospital in 2010. Enrolled in this study was a total of 3,886 individuals who underwent physical examination (height, weight, and waist circumference), laboratory tests (complete blood cell count/differential count, basic chemistry, serologic tests, thyroid function tests, assays for tumor markers, and stool/urine analysis), and renal ultrasonography. According to the exclusion criteria, those with an age below 20 years $(n=2)$, history of primary or secondary hyperparathyroidism, and abnormal renal function (creatinine $>1.2 \mathrm{mg} / \mathrm{dL})(\mathrm{n}=91)$ were excluded. Finally, 3,793 subjects were included.

\section{Data collection}

All subjects completed a questionnaire that requested information on demographic data including age, gender, smoking, alcohol consumption, betel nut chewing, family history, past history (including diabetes mellitus, hypertension, renal stone, etc.), and medication history (including antidiabetic agents, antihypertensive agents, etc.). Waist circumference (to the nearest $0.1 \mathrm{~cm}$ ) was measured at the midpoint between the lower border of the rib and iliac crest. The sitting blood pressure was obtained by the standard blood pressure measurement. A blood sample was drawn after an overnight fast (at least 8 hours). Fasting plasma glucose, serum total cholesterol, HDL-C, triglycerides, and creatinine were measured using the auto-analyzer (Beckman Coulter DxC 800; Beckman Coulter, Inc.). Ultrasonography was operated and interpreted by one of the experienced nephrologists in this hospital. 


\section{Diagnosis of metabolic syndrome}

The diagnostic criteria of metabolic syndrome were as follows: 1) elevated waist circumference: $\geq 90 \mathrm{~cm}$ in males and $\geq 80 \mathrm{~cm}$ in females; 2 ) elevated triglycerides: $\geq 150 \mathrm{mg} / \mathrm{dL}$ $(1.7 \mathrm{mmol} / \mathrm{L})$ (drug treatment for elevated triglycerides was an alternate indicator); 3) reduced HDL-C: $<40 \mathrm{mg} / \mathrm{dL}$ $(1.0 \mathrm{mmol} / \mathrm{L})$ in males and $<50 \mathrm{mg} / \mathrm{dL}(1.3 \mathrm{mmol} / \mathrm{L})$ in females (drug treatment for reduced HDL-C was an alternate indicator); 4) elevated blood pressure: systolic $\geq 130 \mathrm{mmHg}$ and/or diastolic $\geq 85 \mathrm{mmHg}$ (antihypertensive drug treatment in a patient with a history of hypertension was an alternate indicator); and 5) elevated fasting glucose: $\geq 100 \mathrm{mg} / \mathrm{dL}$ (drug treatment for elevated glucose was an alternate indicator). The criteria are based on the IDF and the AHA/NHLBI criteria, which are the same as those of the Ministry of Health and Welfare in Taiwan. Metabolic syndrome was defined as the presence of three or more of these five criteria.

\section{Diagnosis of nephrolithiasis}

The renal ultrasonography was performed and interpreted by nephrologists unaware of the objectives of the study and blinded to the laboratory values. All of the reports were reviewed, and the diagnosis of nephrolithiasis was defined by the demonstration of hyperechoic structure causing acoustic shadowing in kidneys.

\section{Statistical analyses}

Categorical variables are reported as number (percentage) and continuous variables as mean \pm standard deviation. Betweengroup differences were compared using chi-square tests for categorical variables and Student's $t$-tests, Mann-Whitney $U$ test, or analysis of variance for continuous variables. Univariate and multivariate logistic regression models were used to assess the association of metabolic syndrome and its components with nephrolithiasis, with results expressed as odds ratios (ORs) and 95\% confidence intervals (CIs). Statistical analyses were performed using IBM Statistical Package for the Social Sciences (SPSS) version 18.0. All $P$-values are two-tailed, and $P<0.05$ was considered statistically significant.

\section{Results}

The mean age of the 3,793 participants was $46.49 \pm 11.91$ years. The prevalence rate of nephrolithiasis was $16.8 \%(n=639)$. Table 1 shows the demographic characteristics of the nephrolithiasis and non-nephrolithiasis groups. There were significant differences in mean age, body mass index (BMI), waist circumference, blood pressure, triglycerides, HDL, low-density lipoprotein (LDL), fasting glucose, serum uric acid, and creatinine. Urinary $\mathrm{pH}$ showed no significant difference $(P=0.89)$.

Based on the IDF and the AHA/NHLBI criteria, which are same as those of the Ministry of Health and Welfare in Taiwan, the prevalence rate of metabolic syndrome was $25.5 \%$ $(n=967)$. Table 2 lists the demographic characteristics of the metabolic syndrome and non-metabolic syndrome groups. The mean age, gender, BMI, waist circumference, blood pressure, triglycerides, HDL, LDL, fasting glucose, serum uric acid, and urinary $\mathrm{pH}$ were all significantly different between the metabolic syndrome and non-metabolic syndrome

Table I Demographic characteristics of study subjects with and without nephrolithiasis

\begin{tabular}{|c|c|c|c|c|}
\hline Characteristics & $\begin{array}{l}\text { Total } \\
(\text { mean } \pm \text { SD) }\end{array}$ & $\begin{array}{l}\text { Nephrolithiasis } \\
(\text { mean } \pm \text { SD) }\end{array}$ & $\begin{array}{l}\text { Non-nephrolithiasis } \\
\text { (mean } \pm \text { SD) }\end{array}$ & $P$-value \\
\hline Age (years) & $46.49 \pm 11.91$ & $50.05 \pm 10.72$ & $45.77 \pm \mid 2.01$ & $<0.001$ \\
\hline BMI $\left(\mathrm{kg} / \mathrm{m}^{2}\right)$ & $23.93 \pm 3.55$ & $24.76 \pm 3.44$ & $23.77 \pm 2.55$ & $<0.001$ \\
\hline Waist circumference $(\mathrm{cm})$ & $80.22 \pm 9.87$ & $83.16 \pm 9.27$ & $79.62 \pm 9.88$ & $<0.001$ \\
\hline \multicolumn{5}{|l|}{ Blood pressure $(\mathrm{mmHg})$} \\
\hline Systolic & $125.20 \pm 16.70$ & $128.84 \pm 16.95$ & $124.46 \pm 16.56$ & $<0.001$ \\
\hline Diastolic & $81.65 \pm 10.42$ & $84.03 \pm 10.53$ & $81.16 \pm 10.33$ & $<0.001$ \\
\hline Triglycerides (mg/dL) & $1|5.15 \pm| 14.92$ & $133.23 \pm 184.07$ & III.49土94.58 & $<0.001$ \\
\hline HDL cholesterol (mg/dL) & $49.42 \pm 13.85$ & $46.74 \pm 12.47$ & $49.96 \pm 14.05$ & $<0.001$ \\
\hline LDL cholesterol (mg/dL) & $125.43 \pm 30.52$ & $128.85 \pm 32.75$ & $|24.76 \pm 30.0|$ & 0.004 \\
\hline Fasting glucose $(\mathrm{mg} / \mathrm{dL})$ & $98.09 \pm 22.44$ & $|02.37 \pm 28.4|$ & $97.22 \pm 20.93$ & $<0.001$ \\
\hline Serum uric acid (mg/dL) & $5.7 \mathrm{I} \pm \mathrm{I} .43$ & $6.04 \pm 1.49$ & $5.65 \pm 1.42$ & $<0.001$ \\
\hline Urinary $\mathrm{pH}$ & $5.80 \pm 0.85$ & $5.80 \pm 0.82$ & $5.80 \pm 0.85$ & 0.885 \\
\hline Creatinine & $0.79 \pm 0.18$ & $0.82 \pm 0.18$ & $0.78 \pm 0.18$ & $<0.001$ \\
\hline
\end{tabular}

Notes: Continuous variables are presented as mean $\pm \mathrm{SD}$. Conversion to Sl unit factor: triglycerides in $\mathrm{mg} / \mathrm{dL}$ to $\mathrm{mmol} / \mathrm{L}, 0.0113 ; \mathrm{cholesterol}$ in $\mathrm{mg} / \mathrm{dL}$ to $\mathrm{mmol} / \mathrm{L}, 0.0259$; glucose in $\mathrm{mg} / \mathrm{dL}$ to $\mathrm{mmol} / \mathrm{L}, 0.0555$; creatinine in $\mathrm{mg} / \mathrm{dL}$ to $\mu \mathrm{mol} / \mathrm{L}, 88.4$.

Abbreviations: SD, standard deviation; BMI, body mass index; HDL, high-density lipoprotein; LDL, low-density lipoprotein. 


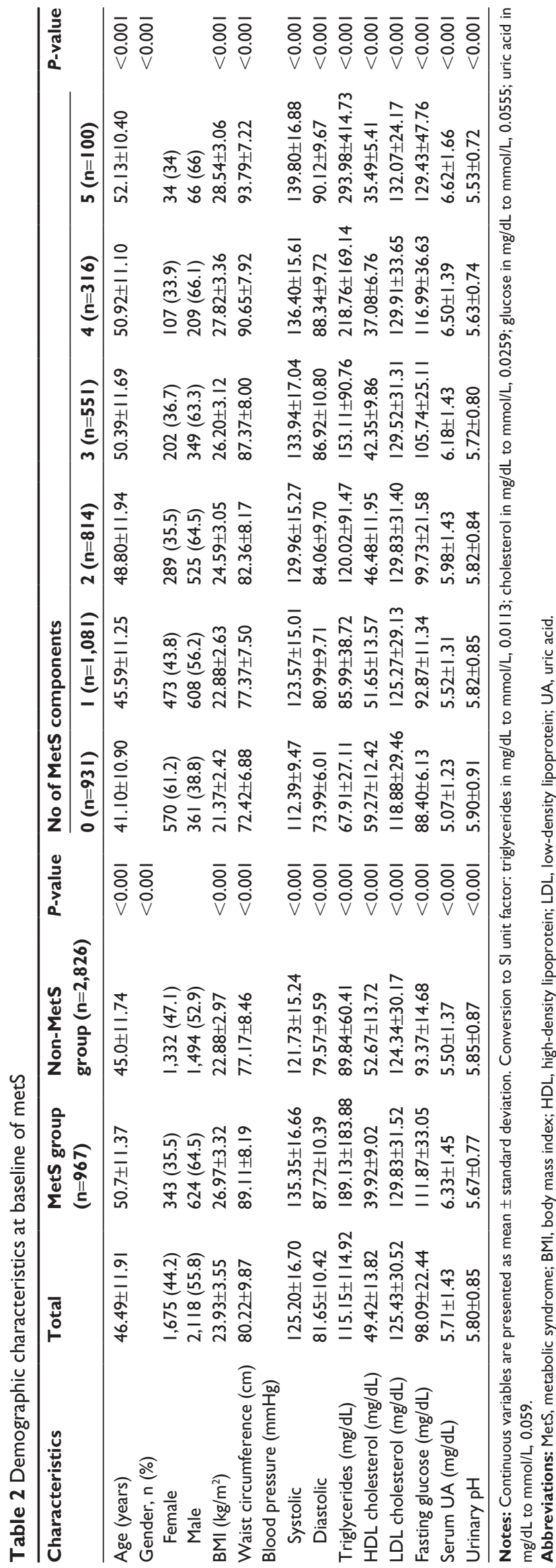

groups. As the number of metabolic syndrome components increased, mean age, BMI, waist circumference, blood pressure, triglycerides, LDL, fasting glucose, and serum uric acid increased (all $P<0.001$ ), whereas HDL and urinary $\mathrm{pH}$ decreased $(P<0.001)$.

Table 3 presents the crude (unadjusted) OR of risk factors associated with nephrolithiasis from the univariate analysis. The metabolic syndrome group was associated with a $73.6 \%$ increased OR of nephrolithiasis compared with the non-metabolic syndrome group (OR 1.736; 95\% CI 1.447-2.084; $P<0.001)$. As the number of metabolic syndrome components increased from one to five, the OR increased from 1.520 to $2.986(P<0.001)$. Males had a significantly higher prevalence rate than females (OR 1.848; 95\% CI 1.543-2.213; $P<0.001)$. Larger waist circumference (OR 1.541; 95\% CI 1.283-1.850; $P<0.001$ ), higher blood pressure (OR 1.825; 95\% CI 1.534-2.172; $P<0.001$ ), decreased HDL (OR 1.222; 95\% CI 1.027-1.455; $P=0.02$ ), increased triglycerides (OR 1.373; 95\% CI 1.128-1.672; $P=0.002$ ), and increased fasting glucose (OR 1.701; $95 \%$ CI 1.423-2.034; $P<0.001$ ) were identified as significant risk factors associated with nephrolithiasis.

After adjusting for all covariates in the multivariate analysis, metabolic syndrome remained a significant risk factor for the nephrolithiasis (multivariable-adjusted OR 1.318; 95\% CI 1.083-1.604; $P=0.006)$. Larger waist circumference (multivariable-adjusted OR 1.338; 95\% CI 1.098-1.631; $P=0.004$ ), higher blood pressure (multivariable-adjusted OR $1.333 ; 95 \%$ CI $1.106-1.607 ; P=0.003$ ), and increased fasting glucose (multivariable-adjusted OR 1.276; 95\% CI 1.0541.546; $P=0.01)$ were all associated with nephrolithiasis. However, triglycerides (multivariable-adjusted OR 1.088; 95\% CI 0.884-1.338; $P=0.43$ ) and HDL (multivariableadjusted OR 1.128; 95\% CI 0.942-1.352; $P=0.19$ ) were not associated with the presence of nephrolithiasis. Urinary $\mathrm{pH}$ also had no significant association with nephrolithiasis (multivariable-adjusted OR 1.066; 95\% CI 0.960-1.183; $P=0.23$ ) (Table 4).

\section{Discussion}

\section{Summary}

Consistent with other previous studies, ${ }^{11-13}$ this study revealed the significantly increased risk of nephrolithiasis associated with metabolic syndrome. Furthermore, when the numbers of metabolic syndrome components increased from one to five, the OR of nephrolithiasis increased from 1.520 to 2.986 . We also found a significant association between nephrolithiasis and abdominal obesity, hypertension, and insulin resistance, 
Table 3 The association of nephrolithiasis with MetS and its components

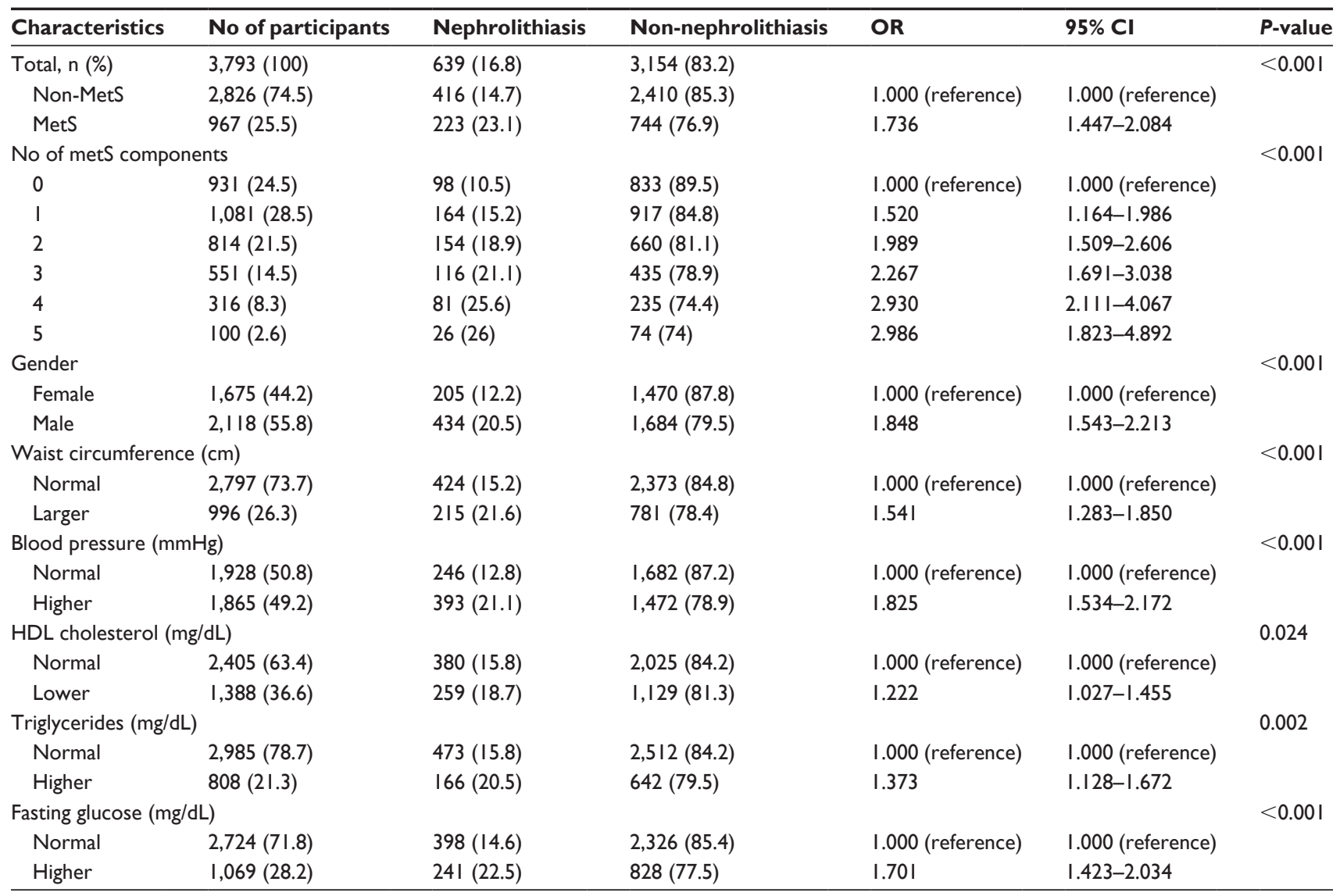

Abbreviations: $\mathrm{OR}$, odds ratio; $\mathrm{Cl}$, confidence interval; MetS, metabolic syndrome; HDL, high-density lipoprotein.

but not with dyslipidemia and urine $\mathrm{pH}$. The association was not causal because this is a cross-sectional study. The possible reasons for this will be discussed in the following paragraphs.

\section{Strengths and limitations}

This study is the first to investigate the correlation of metabolic syndrome and risk of nephrolithiasis in Taiwan. Metabolic syndrome is believed to relate to gallbladder stone and was proven in a previous study, ${ }^{14}$ but the relationship of metabolic syndrome with nephrolithiasis has been less commonly noted. In order to apply this result to the general population, a large number of healthy participants were enrolled and subjected to a comprehensive examination process. To be more precise, this study used the unified definition by the IDF and the AHA/NHLBI which is universally considered as the most acceptable definition and most suitable for the Asian population. ${ }^{1,11}$ There are a number of limitations in this study. First, no causal relationship could be established because this is a cross-sectional study, and not a longitudinal study. Second, because no stone analysis was performed, it is difficult to clarify the definite relationship between

Table 4 Multivariate-adjusted OR $(95 \% \mathrm{Cl})$ of metabolic syndrome components for nephrolithiasis

\begin{tabular}{|c|c|c|}
\hline Characteristics & Adjusted OR ${ }^{\S}(95 \% \mathrm{CI})$ & P-value \\
\hline Metabolic syndrome & $1.318(1.083-1.604)$ & $0.006 *$ \\
\hline Waist circumference ( $\geq 90 \mathrm{~cm}$ for males and $\geq 80 \mathrm{~cm}$ for females) & $1.338(1.098-1.631)$ & $0.004^{*}$ \\
\hline Blood pressure $(\geq 130 / 85 \mathrm{mmHg})$ & $1.333(1.106-1.607)$ & $0.003^{*}$ \\
\hline Triglycerides ( $\geq 150 \mathrm{mg} / \mathrm{dL})$ & $\mathrm{I} .088(0.884-1.338)$ & 0.426 \\
\hline HDL cholesterol ( $<40 \mathrm{mg} / \mathrm{dL}$ in males and $<50 \mathrm{mg} / \mathrm{dL}$ in females) & $\mathrm{I} .128(0.942-1.352)$ & 0.190 \\
\hline Fasting glucose ( $\geq 100 \mathrm{mg} / \mathrm{dL})$ & $\mathrm{I} .276(\mathrm{I} .054-\mathrm{I} .546)$ & $0.013^{*}$ \\
\hline Urine $\mathrm{pH}$ & $1.066(0.960-1.183)$ & 0.234 \\
\hline
\end{tabular}

Notes: $\AA^{A}$ Adjusted for age, gender, serum uric acid, and creatinine. $* P<0.05$.

Abbreviations: $\mathrm{OR}$, odds ratio; $\mathrm{Cl}$, confidence interval; $\mathrm{HDL}$, high-density lipoprotein. 
metabolic syndrome and the different types of kidney stones. Third, the urine $\mathrm{pH}$ was not measured by $\mathrm{pH}$ electrode, and spot urine $\mathrm{pH}$ was tested by dipstick. Determination of urine $\mathrm{pH}$ by methods other than $\mathrm{pH}$ electrode is subject to error. Moreover, urinary $\mathrm{pH}$ has cyclic variations throughout the day. Finally, selection bias might exist because the subjects voluntarily received the health examinations.

\section{Comparison with existing literature}

Abdominal obesity was associated with a 1.338-fold increased risk of nephrolithiasis in our study. A prior analysis also found a positive association between waist circumference and risk of nephrolithiasis. ${ }^{15}$ However, the mechanism whereby obesity increases the risk of nephrolithiasis is uncertain. The production of free fatty acid related to visceral obesity results in increased glucose, triglycerides, very LDL, and LDL and decreased HDL in the liver, resulting in insulin resistance. ${ }^{11}$ The low urine $\mathrm{pH}$ caused by insulin resistance is considered to be an important factor in urine lithogenicity, especially in uric acid stone formation. Increasing calcium, oxalate, and uric acid by excess nutritional intake has also been reported, ${ }^{16}$ and Powell et al ${ }^{17}$ reported that urinary excretion of sodium, calcium, magnesium, citrate, sulfate, phosphate, oxalate, uric acid, and cystine was increased in the obese group. After performing a cohort study that surveyed participants' urine $\mathrm{pH}$ and 24-hour urinary excretion of calcium, oxalate, citrate, uric acid, sodium, magnesium, potassium, and phosphate, Taylor and $\mathrm{Curhan}^{18}$ noted that the association between nephrolithiasis and obesity may come from these excess excretions of urinary materials, although other retrospective population studies did not disclose such association or similar relationships in well-established calcium stone formers. Therefore, we concluded that the significantly positive relationship between nephrolithiasis and obesity in our study was reliable and that further study to clarify the mechanisms should be undertaken.

Our results confirmed that elevated blood pressure ( $\geq 130 / 85 \mathrm{mmHg}$ ) was independently associated with the development of nephrolithiasis, with a 1.333-fold increased risk. This epidemiological evidence is consistent with earlier studies including either cross-sectional studies or prospective cohort studies. ${ }^{19-21}$ Still, the causative relationship and pathophysiologic mechanisms remain uncertain. The calcium leak hypothesis was considered to be a possible mechanism, with Borghi et $\mathrm{al}^{22}$ suggesting that hypercalciuria is an important risk factor of the calcium oxalate calculi formation. Obligado and Goldfarb proposed that increased urinary calcium excretion (hypercalciuria) caused by the abnormal nephron calcium handling in a hypertensive population is an important risk factor of stone formation. ${ }^{9}$ However, some evidence suggests that there is no association between hypertension and hypercalciuria from the analysis of urine compositions..$^{23,24}$ On the other hand, we found that low urine citrate was significantly associated with hypertension.

Our study reveals that there was a 1.276-fold increased risk of nephrolithiasis in participants with elevated fasting glucose. There have been several epidemiological reports that strongly support the correlation between diabetes mellitus and nephrolithiasis in western countries. ${ }^{25-29}$ In Asian population, a review article by Liu et al in 2015 showed that there was a definite association between diabetes and urolithiasis. ${ }^{30}$ There are two Taiwanese cohort studies that reported an increased risk of urolithiasis in a diabetic group. ${ }^{31,32}$ Insulin resistance has been previously considered the most correlative factor between the metabolic syndrome and nephrolithiasis. ${ }^{10,33}$ Ando et al performed a homeostasis model assessment of insulin resistance (HOMA-IR) and found significantly higher HOMA-IR and insulin in women with kidney stones. ${ }^{34}$ The relationship between insulin resistance and uric acid stones is well known, with the decreased production and transport of ammonia caused by insulin resistance leading to lower urine $\mathrm{pH}$ being the most widely promoted hypothesis. ${ }^{10,11,35}$ The unduly acidic urine interferes with the uric acid solubility and then leads to precipitation and increased risk of uric acid stone.

Although more acidic urine was found in the metabolic syndrome group, there was no significant association between urine $\mathrm{pH}$ and nephrolithiasis in our study. We hypothesize two reasons for this. First, calcium kidney stones account for the majority of nephrolithiasis, and the mechanism of calcium stone formation in metabolic syndrome is different from that of uric acid stones, as mentioned. The hypothesis of the relationship between calcium stone and metabolic syndrome includes supersaturation hypothesis, Randall's plaques, and the oxidative stress with inflammation. ${ }^{36}$ Cupisti et al suggested that in calcium stone formers, insulin resistance may decrease urinary citrate excretion. ${ }^{37}$ Unlike hyperacid urine in uric stone formation, decreased urinary citrate excretion occurring in calcium stone formation reveals no significant reduction of urine $\mathrm{pH}$. The other reason might be that even in the uric acid stone formation, urine $\mathrm{pH}$ is not the only determining factor because lithogenicity is a complex physicochemical process. According to the review of Wong et al, only two-thirds of uric stone formers had undue acidity in urine related to insulin resistance. ${ }^{11}$ However, bias and errors may exist because the spot urine $\mathrm{pH}$ testing by 
dipstick is not an accurate method for evaluating the patients with urolithiasis.

\section{Implications for research and/or practice}

In conclusion, this study reinforced the association between metabolic syndrome and nephrolithiasis. Abdominal obesity, elevated blood pressure, and increased fasting glucose were all independently related to nephrolithiasis. Therefore, adequate lifestyle modification and proper treatment in metabolic syndrome management may contribute to nephrolithiasis prevention.

\section{Acknowledgments}

This study was supported in part by Health Examination Center and Department of Family Medicine of Changhua Christian Hospital. The funders had no role in study design, data collection and analysis, decision to publish, or preparation of the manuscript. No additional external funding was received for this study.

\section{Author contributions}

Y-T Liu did the main work of preparing the manuscript. P-Y Yang, Y-W Yang, H-Y Sun, and I-C Lin contributed to the design of the study, data collection, and drafting of the manuscript. All authors contributed toward data analysis, drafting and critically revising the paper and agree to be accountable for all aspects of the work.

\section{Disclosure}

The authors report no conflicts of interest in this work.

\section{References}

1. Eckel RH, Grundy SM, Zimmet PZ. The metabolic syndrome. Lancet. 2005;365(9468):1415-1428.

2. Eckel RH, Alberti KG, Grundy SM, Zimmet PZ. The metabolic syndrome. Lancet. 2010;375(9710):181-183.

3. Alberti KG, Eckel RH, Grundy SM, et al; International Diabetes Federation Task Force on Epidemiology and Prevention; National Heart, Lung, and Blood Institute; American Heart Association; World Heart Federation; International Atherosclerosis Society; International Association for the Study of Obesity. Harmonizing the metabolic syndrome: a joint interim statement of the International Diabetes Federation Task Force on Epidemiology and Prevention; National Heart, Lung, and Blood Institute; American Heart Association; World Heart Federation; International Atherosclerosis Society; and International Association for the Study of Obesity. Circulation. 2009;120(16): 1640-1645.

4. Yeh CJ, Chang HY, Pan WH. Time trend of obesity, the metabolic syndrome and related dietary pattern in Taiwan: from NAHSIT 1993-1996 to NAHSIT 2005-2008. Asia Pac J Clin Nutr. 2011;20(2):292-300.

5. Stamatelou KK, Francis ME, Jones CA, Nyberg LM, Curhan GC. Time trends in reported prevalence of kidney stones in the United States: 1976-1994. Kidney Int. 2003;63(5):1817-1823.
6. Sakhaee K. Recent advances in the pathophysiology of nephrolithiasis. Kidney Int. 2009;75(6):585-595.

7. Romero V, Akpinar H, Assimos DG. Kidney stones: a global picture of prevalence, incidence, and associated risk factors. Rev Urol. 2010; 12(2-3):e86-e96.

8. Ramello A, Vitale C, Marangella M. Epidemiology of nephrolithiasis. J Nephrol. 2000;13(Suppl 3):S45-S50.

9. Obligado SH, Goldfarb DS. The association of nephrolithiasis with hypertension and obesity: a review. Am J Hypertens. 2008;21(3): 257-264.

10. Sakhaee K, Maalouf NM. Metabolic syndrome and uric acid nephrolithiasis. Semin Nephrol. 2008;28(2):174-180.

11. Wong YV, Cook P, Somani BK. The association of metabolic syndrome and urolithiasis. Int J Endocrinol. 2015;2015:570674.

12. Jeong IG, Kang T, Bang JK, et al. Association between metabolic syndrome and the presence of kidney stones in a screened population. Am J Kidney Dis. 2011;58(3):383-388.

13. Filgueiras Pinto Rde S, Almeida JR, Kang HC, Rosa ML, Lugon JR. Metabolic syndrome and associated urolithiasis in adults enrolled in a community-based health program. Fam Pract. 2013;30(3):276-281.

14. Lin IC, Yang YW, Wu MF, et al. The association of metabolic syndrome and its factors with gallstone disease. BMC Fam Pract. 2014;15:138.

15. Taylor EN, Stampfer MJ, Curhan GC. Obesity, weight gain, and the risk of kidney stones. JAMA. 2005;293(4):455-462.

16. Asplin JR. Obesity and urolithiasis. Adv Chronic Kidney Dis. 2009;16(1): 11-20.

17. Powell CR, Stoller ML, Schwartz BF, et al. Impact of body weight on urinary electrolytes in urinary stone formers. Urology. 2000;55(6): 825-830.

18. Taylor EN, Curhan GC. Body size and 24-hour urine composition. Am J Kidney Dis. 2006;48(6):905-915.

19. Cirillo M, Laurenzi M. Elevated blood pressure and positive history of kidney stones: results from a population-based study. $J$ Hypertens Suppl. 1988;6(4):S485-S486.

20. Cappuccio FP, Strazzullo P, Mancini M. Kidney stones and hypertension: population based study of an independent clinical association. BMJ. 1990;300(6734):1234-1236.

21. Cappuccio FP, Siani A, Barba G, et al. A prospective study of hypertension and the incidence of kidney stones in men. J Hypertens. 1999;17(7): 1017-1022.

22. Borghi L, Meschi T, Guerra A, et al. Essential arterial hypertension and stone disease. Kidney Int. 1999;55(6):2397-2406.

23. Taylor EN, Mount DB, Forman JP, Curhan GC. Association of prevalent hypertension with 24-hour urinary excretion of calcium, citrate, and other factors. Am J Kidney Dis. 2006;47(5):780-789.

24. Losito A, Nunzi EG, Covarelli C, Nunzi E, Ferrara G. Increased acid excretion in kidney stone formers with essential hypertension. Nephrol Dial Transplant. 2009;24(1):137-141.

25. Taylor EN, Stampfer MJ, Curhan GC. Diabetes mellitus and the risk of nephrolithiasis. Kidney Int. 2005;68(3):1230-1235.

26. Lieske JC, de la Vega LS, Gettman MT, et al. Diabetes mellitus and the risk of urinary tract stones: a population-based case-control study. Am J Kidney Dis. 2006;48(6):897-904.

27. Daudon M, Traxer O, Conort P, Lacour B, Jungers P. Type 2 diabetes increases the risk for uric acid stones. J Am Soc Nephrol. 2006;17(7): 2026-2033.

28. Kadlec AO, Greco K, Fridirici ZC, Hart ST, Vellos T, Turk TM. Metabolic syndrome and urinary stone composition: what factors matter most? Urology. 2012;80(4):805-810.

29. Weinberg AE, Patel CJ, Chertow GM, Leppert JT. Diabetic severity and risk of kidney stone disease. Eur Urol. 2014;65(1):242-247.

30. Liu LH, Kang R, He J, Zhao SK, Li FT, Zhao ZG. Diabetes mellitus and the risk of urolithiasis: a meta-analysis of observational studies. Urolithiasis. 2015;43(4):293-301.

31. Chung SD, Chen YK, Lin HC. Increased risk of diabetes in patients with urinary calculi: a 5-year followup study. J Urol. 2011;186(5): 1888-1893. 
32. Chen HS, Su LT, Lin SZ, Sung FC, Ko MC, Li CY. Increased risk of urinary tract calculi among patients with diabetes mellitus - a population-based cohort study. Urology. 2012;79(1):86-92.

33. Li H, Klett DE, Littleton R, Elder JS, Sammon JD. Role of insulin resistance in uric acid nephrolithiasis. World J Nephrol. 2014;3(4): 237-242.

34. Ando R, Suzuki S, Nagaya T, et al. Impact of insulin resistance, insulin and adiponectin on kidney stones in the Japanese population. Int J Urol. 2011;18(2):131-138.
35. Sakhaee K, Maalouf NM, Sinnott B. Clinical review. Kidney stones 2012: pathogenesis, diagnosis, and management. J Clin Endocrinol Metab. 2012;97(6):1847-1860.

36. Domingos F, Serra A. Metabolic syndrome: a multifaceted risk factor for kidney stones. Scand J Urol. 2014;48(5):414-419.

37. Cupisti A, Meola M, D'Alessandro C, et al. Insulin resistance and low urinary citrate excretion in calcium stone formers. Biomed Pharmacother. 2007;61(1):86-90.

\section{Publish your work in this journal}

Therapeutics and Clinical Risk Management is an international, peerreviewed journal of clinical therapeutics and risk management, focusing on concise rapid reporting of clinical studies in all therapeutic areas, outcomes, safety, and programs for the effective, safe, and sustained use of medicines. This journal is indexed on PubMed Central, CAS,
EMBase, Scopus and the Elsevier Bibliographic databases. The manuscript management system is completely online and includes a very quick and fair peer-review system, which is all easy to use. Visit http://www.dovepress.com/testimonials.php to read real quotes from published authors.

Submit your manuscript here: http://www.dovepress.com/therapeutics-and-clinical-risk-management-journal 